\title{
Psychosocial functioning in adolescents with non-suicidal self-injury: the roles of childhood maltreatment, borderline personality disorder and depression
}

Denisa Ghinea ${ }^{1 \dagger}$, Anna Fuchs $^{1 \dagger}$, Peter Parzer ${ }^{1}$, Julian Koenig ${ }^{1,2}$, Franz Resch ${ }^{1}$ and Michael Kaess ${ }^{1,2^{*}}$

\begin{abstract}
Background: There is a lack of studies examining psychosocial functioning in patients with non-suicidal self-injury (NSSI), especially in adolescents, and rates of impaired functioning in existing literature vary considerably. These variations may be attributable to further risk factors that influence psychosocial functioning. Thus, the aim of the study was to examine whether adolescent NSSI patients with childhood maltreatment (CM), a known risk factor for lower psychosocial functioning, may differ from adolescent NSSI patients without CM, and whether these differences may be explained by the severity of comorbid disorders. Specifically, we examined whether severity of borderline personality disorder (BPD), depression and posttraumatic stress disorder may explain differences in psychosocial functioning in NSSI patients with and without CM.
\end{abstract}

Methods: Data of 368 adolescents with NSSI disorder from an outpatient clinic were analyzed using structural equation modeling. Clinicans' rating of the Global Assessment of Functioning Scale (GAF) was collected, in addition to clinical interviews.

Results: Results indicate that GAF scores were lower among NSSI patients with CM and that the difference in psychosocial functioning between these groups was explained by BPD and depression severity.

Conclusions: Psychosocial functioning in NSSI patients varies depending on whether they have experienced CM or not. Specifically, these differences seem to be attributable to higher BPD and depression severity in adolescent NSSI patients with CM. Clinicians should ensure to assess CM and focus on BPD and depression severity in this population. Treatment of BPD and depression may notably reduce psychosocial impairment in NSSI patients with CM.

Keywords: Childhood maltreatment, Depression, Borderline personality disorder, Psychosocial functioning, Structural equation model

\footnotetext{
*Correspondence: michael.kaess@upd.ch

Denisa Ghinea and Anna Fuchs are shared first authorship.

'Department of Child and Adolescent Psychiatry, Centre for Psychosocial

Medicine, University of Heidelberg, Heidelberg, Germany

2University Hospital of Child and Adolescent Psychiatry and Psychotherapy,

University of Bern, Bern, Switzerland
}

(c) The Author(s). 2021 Open Access This article is licensed under a Creative Commons Attribution 4.0 International License, which permits use, sharing, adaptation, distribution and reproduction in any medium or format, as long as you give appropriate credit to the original author(s) and the source, provide a link to the Creative Commons licence, and indicate if changes were made. The images or other third party material in this article are included in the article's Creative Commons licence, unless indicated otherwise in a credit line to the material. If material is not included in the article's Creative Commons licence and your intended use is not permitted by statutory regulation or exceeds the permitted use, you will need to obtain permission directly from the copyright holder. To view a copy of this licence, visit http://creativecommons.org/licenses/by/4.0/ The Creative Commons Public Domain Dedication waiver (http://creativecommons.org/publicdomain/zero/1.0/) applies to the data made available in this article, unless otherwise stated in a credit line to the data. 


\section{Introduction}

Psychosocial functioning describes a person's ability to play their part in society by carrying out roles and performing activities in daily life such as self-preservation and basic living skills, work, school or leisure activities and interactions with their social environment [1, 2]. There is some indication that psychosocial functioning is significantly reduced in populations engaging in nonsuicidal self-injury (NSSI) [3-5]. NSSI is defined as the direct, intentional destruction of one's bodily tissue without the intent to die [6]. It is highly prevalent in adolescent populations with rates around $17-18 \%[7,8]$ and rates up to $60 \%$ in child and adolescent clinical settings [9]. NSSI peaks around the age of 15 with remission in young to middle adulthood [10]. It is known to be associated to a wide range of psychiatric conditions $[11,12]$, nonetheless also occurring as an own diagnostic entity [5].

Studies that examine psychosocial functioning in NSSI populations are generally scarce, and existing work has mostly focused on adult populations [3, 4]. Rates of impaired psychosocial functioning in NSSI samples vary, with $65 \%$ [4] to $92 \%$ [13] in community samples, and 20 to $33 \%$ [14] and over $98 \%$ [3] in clinical samples. These variations may be partly explained by differences in assessment of psychosocial functioning. To our knowledge, In-Albon, Ruf \& Schmid (2013) was the only study assessing psychosocial functioning in a moderately sized sample of 73 adolescents using clinical ratings [14]. Expert-based clinical ratings offer more beneficial validity, whereas self-ratings are often subject to misperception or cognitive biases $[15,16]$. Variations in psychosocial functioning in NSSI populations may also be attributable to the population under study (adults vs. adolescents) or further risk factors such as childhood maltreatment $(\mathrm{CM})$ or comorbidity. More work is needed to highlight psychosocial functioning in adolescent NSSI samples which implements clinical ratings of functioning, features larger sample sizes and sheds light on potential risk factors in this context.

While studies on NSSI and psychosocial functioning are rare, a link between childhood maltreatment (CM), i.e. experiences of sexual, physical and emotional abuse as well as physical and emotional neglect during childhood and adolescence, and functional impairments has been reliably established [17]. The often complex sequelae of CM have been shown to impact various domains of psychosocial functioning: Individuals with $\mathrm{CM}$ show deficits in interpersonal functioning [18], high risk of revictimization $[19,20]$, higher rates of criminality and high risk of incarceration in adulthood [21]. CM has further been shown to predict school problems [22, 23] and difficulties in academic and occupational settings such as truancy or lower likelihood to attend college. Above all, however, $\mathrm{CM}$ is one of the most salient risk factors for mental disorders such as major depression, borderline personality disorder (BPD), or posttraumatic stress disorder (PTSD), and has been linked with maladaptive regulatory functioning and coping in behavior and neurobiology [17, 24-26]. Evidence from longitudinal data suggests that $\mathrm{CM}$ predicts adolescent psychological and behavioral problems above and beyond the effects of other early risk factors such as poverty or family stress [27]. Rogosch and colleagues [28] showed that CM leads to problems in affective and emotional processing that in turn lead to problems in peer relationships. These findings are supported by neurobiological evidence suggesting complex disturbances in neurodevelopmental pathways in individuals with CM [26]. CM and subsequent neurobiological alterations may also contribute to maladaptive coping patterns inherent in psychiatric disorders which in turn foster significant intra- and interpersonal problems in various domains long into adulthood [29]. In line with this, prior work has debated whether mentally ill individuals with or without CM may represent biologically distinguishable subtypes [30, 31].

Adolescents engaging in NSSI frequently report CM [9-11]. While several studies suggest a crucial role of CM in NSSI development $[9,32,33]$, there is also a substantial group of individuals engaging in NSSI who do not report CM [9, 34]. It is yet unclear whether these two groups differ with respect to their levels of psychosocial functioning. As CM is associated with a significantly higher risk for mental disorders [24, 35], it is possible that $\mathrm{CM}$ may represent an additional risk factor that further diminishes the availability of adequate behavioral and physiological coping strategies in adolescents with NSSI, who then may present with lower psychosocial functioning.

Clinical research has suggested that $\mathrm{CM}$ increases mental disorder symptom severity, comorbidity and reduces treatment response in patients [36-43]. Both a higher symptom load and potentially reduced treatment benefits would put NSSI patients with CM at risk for lower psychosocial functioning compared with NSSI patients without CM. However, a potential role of mental disorder severity in differentiating psychosocial functioning in NSSI adolescents with or without CM has not been tested. Two disorders may be particularly relevant in context of NSSI, CM and psychosocial functioning: BPD and depression are most frequently diagnosed in adolescents with NSSI [44, 45] and are strongly linked with psychosocial impairment [46-48]. Moreover, both BPD [49-51] and depression [36-38, 52] are among the disorders most frequently developed after experiences of CM. CM shows stronger associations with BPD than with other diagnoses both in adolescence [49] and 
adulthood [53, 54], and more severe $\mathrm{CM}$ has been found to be associated with higher levels of BPD in NSSI adolescents specifically [55]. CM is further associated with a higher risk of developing PTSD [56-58], however, there are studies suggesting that in adolescent samples, only a low percentage $(13 \%)$ of adolescents with CM meet criteria for a PTSD diagnosis [59]. Similarly, data from a large clinical sample shows that a PTSD diagnosis in adolescents with NSSI (and in part CM) is much less frequently reported than BPD or depression [45]. Still, PTSD diagnosis should be controlled for when investigating the role of BPD and depression in NSSI adolescents with or without $\mathrm{CM}$.

\section{The present study}

Considering the lack of studies examining psychosocial functioning in adolescents engaging in NSSI, our aim was to investigate psychosocial functioning in a large clinical NSSI-sample and to examine whether adolescents with or without CM may present with different levels of psychosocial functioning. In addition, we examined whether mental disorder severity may explain the difference in psychosocial functioning between those groups. We specifically focused on BPD and depression, as those disorders have been closely linked with CM but also with impairments in psychosocial functioning and are frequent in clinical samples of adolescents engaging in NSSI [45, 46, 48]. Further, we examined whether a PTSD diagnosis may explain additional variance in psychosocial functioning [58].

\section{Methods}

\section{General procedure and study sample}

Subjects for the present analyses were drawn from a consecutive clinical sample of adolescents presenting at the specialized German outpatient clinic for risk-taking and self-harm behavior (AtR!Sk; Ambulanz für Risikoverhalten und Selbstschädigung) at the Clinic for Child and Adolescent Psychiatry, Centre of Psychosocial Medicine, University of Heidelberg. AtR!Sk aims to clinically assess the engagement in risk-taking (i.e., binge-drinking, drug abuse, excessive media or internet use, promiscuity, delinquent behavior) and/or self-harm behavior (NSSI and/ or suicide attempts) in adolescents aged 12-17 in order to refer them to subsequent treatment [60]. The data were collected at baseline of the ongoing AtR!Sk cohort study, which was approved by the Ethical Committee of the Medical Faculty, Heidelberg University, Germany (Study: ID S-449/2013) in accordance to the Declaration of Helsinki. Informed and written consent was provided by adolescents and their parents or other caregivers prior to inclusion in the study. Only adolescents with NSSI-disorder according to DSM-5 ( $\geq 5$ acts of NSSI in the past year) and complete data were included in the present analyses. The final sample comprised $n=368$ adolescents ( $n=335$ female, 91.03\%; mean age 14.92 years, $S D=1.43$ ). Based on the NSSI sample two sub-groups were generated: NSSI without CM (NSSI only, $n=107$ ) and NSSI with CM (NSSI+CM, $n=261)$. The two groups did not differ on age and sex distribution, but significantly differed on school type, number of BPD and depression score (further details see results).

\section{Clinical assessment \\ Semi-structured interviews}

To assess BPD symptoms dimensionally, the German version [61] of the Structured Clinical Interview for DSM-IV-Axis II (SCID-II; [62]) was used. The SCID-II is widely known to be suitable for the use in adolescents [63].

The German version of the Self-Injurious Thoughts and Behavior Interview (SITBI-G; [64]) was used to assess NSSI and suicidal behavior. The SITBI-G shows excellent reliability and validity in adolescent samples [64].

The German version of the Mini-International Neuropsychiatric Interview for Children and Adolescents (M.I.N.I-KID 6.0; [65]) was conducted to assess current psychiatric diagnoses. The M.I.N.I.-KID is a brief structured clinician rated diagnostic interview for DSM-IV and ICD-10 psychiatric disorders for children and adolescents aged 6-19 years and has demonstrated good reliability and validity [66].

All interviews were carried out by experienced clinicians in the field of adolescent BPD. Study therapists were clinical psychologists (Master in clinical psychology) who were in training to become licensed psychotherapists, and in addition, training to become DBT-A therapists. They already completed their intermediate exams after 1.5 years. Within AtR!Sk, assessors underwent regular reliability checks. To check for inter-rater reliability, audiotaped interviews of each clinician, consisting of the M.I.N.I.-Kid, the SCID II (borderline, avoidant, dependent and antisocial personality disorder), as well as the SITBI-G were recorded. Interviews were assessed by independent second raters blind to the first raters' scores and diagnoses. Concerning the SITBI-G, very good to perfect agreements were found within the inter-rater reliability checks ( $\mathrm{ss}=0.77-1.00)$. Regarding the SCID II, diagnostic agreement for full-threshold BPD was at $93.6 \%$.

\section{Self-report measures}

Based on the Children's Depression Inventory [67] the German Depressions-Inventar für Kinder und Jugendliche (DIKJ; [68]) was used as a self-report measure to assess depression symptoms in adolescents in the last 2 weeks based on diagnostic criteria for depressive disorder. The DIKJ demonstrated good validity and reliability in 
clinical samples [68] and $\alpha=0.87$ in the current sample. $\mathrm{CM}$ was evaluated with the German version [69] of the Childhood Experience of Care and Abuse Questionnaire (CECA.Q; [70]). The CECA. Q assesses various types of early traumatic childhood experiences retrospectively. It describes experiences of parental antipathy, neglect, and abuse before the age of 17 years. The German version of the CECA. Q showed good internal consistency for each subscale (Cronbach's $\alpha$ from 0.88 to 0.92 ) and retest reliability (Cohen's $\mathrm{k}$ from 0.78 to 0.93) [69]. For the present analyses a dichotomous variable (CM: yes/no) was generated.

\section{Clinical rating of psychosocial functioning}

Psychological, social and occupational functioning were assessed at the end of the diagnostic interview with the Global Assessment of Functioning Scale (GAF), a numerical rating scale from 1 to 100 usually reported on the axis $\mathrm{V}$ of the multiaxial diagnostic system in DSM-IV [71]. The higher the score, the better the current level of psychosocial functioning. A GAF score between 41 and 50 indicates serious symptoms (e.g., suicidal ideation, severe obsessional rituals, frequent shoplifting) or any serious impairment in social, occupational, or school functioning (e.g., no friends, unable to keep a job, cannot work). GAF scores were assessed by experienced clinicians in the field of adolescent NSSI.

\section{Statistical analyses}

To test differences in GAF mean scores in the NSSI only and NSSI+CM groups, the two groups were compared with analysis of variance (ANOVA). Because of significant differences in sex distribution and school type these variables were added as covariates in the adjusted model (ANCOVA). To analyze whether BPD and depression severity may explain the differences in GAF scores between the two groups, first descriptive pairwise correlations between all dimensional variables (number of BPD symptoms assessed via SCID-II, depression assessed via DIKJ and GAF) and age were calculated to test for associations and confounding effects between these variables of interest. To test the effect of sex on BPD, depression and GAF point biserial correlation effect sizes were calculated. Reported $p$-values stem from t-tests, respectively. Šidák-correction was used for correction of multiple comparisons. Mediational hypotheses were tested by employing structural equation modelling (SEM) with maximum likelihood (ML) estimation. The model tested whether CM predicted a lower level of psychosocial functioning (lower GAF) directly and indirectly via BPD features and depression symptoms. The full model included all paths between the variables $\mathrm{CM}$, BPD, depression and GAF. To adjust for PTSD we integrated categorial PTSD diagnosis in the first model.
Goodness of fit (GOF) was assessed using the comparative fit index (CFI), the Tucker Lewis Index (TLI) and the root mean square error of approximation (RMSEA). RMSEA $\geq 0$ and $\leq 0.05$, CFI $\geq 0.97$ and TLI $\geq 0.97$ are indicators of a good model fit [72]. Effects were tested by normal-based bootstrapped confidence intervals (CIs). All analyses were performed using Stata 15.1 (Version 15.1; StataCorp LP, College Station, TX, US) and alpha set to .05 .

\section{Results \\ Descriptive analyses \\ Total sample}

The total sample consisted of $n=368$ adolescents meeting DSM-5 criteria for NSSI. Psychiatric diagnoses within the AtR!Sk cohort were classified based on the International classification of diseases according to WHO (ICD-10; [73]). The most frequently met comorbid disorders were affective disorders (F3) $(n=249$, $67.66 \%$, and of those $n=231,62.77 \%$ with a current depression diagnosis), and personality disorders (F6) $(n=$ $181,49.18 \%$, out of whom $n=137,37.23 \%$ met criteria for full-threshold BPD), followed by neurotic, stressrelated, and somatoform disorders (F4) ( $n=158,42.93 \%$, of those $n=24,6.52 \%$ with a PTSD diagnosis), and behavioral and emotional disorders with onset usually occurring in childhood and adolescence (F9) $(n=102$, $27.72 \%)$. A mean GAF score of $47.89(S D=10.94)$ was reported which indicates serious symptoms. The mean number of BPD criteria in the total sample was 3.75 $(S D=2.19)$. The mean DIKJ score was 30.94 $(S D=8.72)$, corresponding to a percentile rank of 98.7 .

\section{Subgroups}

To test differences in GAF scores, the total NSSI sample was split in two subgroups: NSSI without CM (NSSI only) $(n=107)$ and NSSI+CM $(n=261)$. Of those with $\mathrm{CM}, n=93$ (25.62\% of the total sample) reported sexual abuse, $n=211$ (58.29\%) experienced antipathy from their caregivers, $n=154$ (42.66\%) neglect and $n=96(26.30 \%)$ physical abuse. Detailed sociodemographic and clinical characteristics between the groups are reported in Table 1 . The two groups did not differ regarding their sex $\left(\chi_{(1)}^{2}=3.13, p=0.077\right)$ and age $\left(\mathrm{F}_{(1,366)}=0.76, p=\right.$ $0.384)$, but significantly differed in school type $\left(\chi_{(3)}^{2}=\right.$ 14.16, $p=0.003)$, number of BPD criteria met $\left(\mathrm{F}_{(1,366)}=\right.$ 21.68, $p<0.001)$ and depression severity in the DIKJ $\left(\mathrm{F}_{(1,366)}=21.39, p<0.001\right)$. The $\mathrm{NSSI}+\mathrm{CM}$ group endorsed more BPD criteria (4.08 vs. 2.94) and greater depression severity (32.25 vs. 27.75).

\section{Group differences}

The mean GAF score in the NSSI only group was 50.92 $(S D=12.13)$ vs. $46.64(S D=10.18)$ in the NSSI+CM group. 
Table 1 Sociodemographic and main outcome variables within the NSSI sample

\begin{tabular}{|c|c|c|c|c|c|}
\hline & \multicolumn{2}{|c|}{ NSSI only $(n=107)$} & \multicolumn{2}{|c|}{ NSSI + ACEs $(n=261)$} & \multirow[t]{2}{*}{$p$} \\
\hline & $M$ & $S D$ & $M$ & $S D$ & \\
\hline Age & 14.82 & 1.55 & 14.97 & 1.38 & 0.401 \\
\hline BPD criteria & 2.94 & 2.05 & 4.08 & 2.17 & $<0.001$ \\
\hline DIKJ & 27.75 & 8.47 & 32.25 & 8.49 & $<0.001$ \\
\hline \multirow[t]{2}{*}{ GAF } & 50.93 & 12.13 & 46.64 & 10.18 & $<0.001$ \\
\hline & $N$ & $\%$ & $N$ & $\%$ & \\
\hline Females & 93 & 86.92 & 242 & 92.72 & 0.077 \\
\hline School type ${ }^{a}$ & & & & & 0.003 \\
\hline Hauptschule & 7 & 6.54 & 31 & 11.92 & \\
\hline Realschule & 28 & 26.17 & 99 & 37.69 & \\
\hline Gymnasium & 57 & 53.27 & 85 & 32.69 & \\
\hline Other & 15 & 14.02 & 46 & 17.70 & \\
\hline Household composition & & & & & 0.181 \\
\hline With biological mother & 92 & 86.79 & 192 & 75.89 & \\
\hline With other mother figure & 4 & 3.78 & 11 & 4.35 & \\
\hline With no mother figure & 10 & 9.43 & 50 & 19.76 & \\
\hline With biological father & 62 & 60.78 & 111 & 46.25 & \\
\hline With other father figure & 11 & 10.79 & 39 & 16.25 & \\
\hline With no father figure & 29 & 28.43 & 90 & 37.50 & \\
\hline Residential youth service & 5 & 4.67 & 34 & 13.03 & \\
\hline
\end{tabular}

aHauptschule: 9 years of elementary school; Realschule: 6 years of school after 4 years of elementary school, terminating with a secondary school level-I certificate; Gymnasium: 8 years of school after 4 years of elementary school, terminating with the general qualification for university entrance. Percentage scores take account of missing values

Group differences on GAF based on single data points are illustrated in Fig. 1. ANCOVA yielded significant differences between the groups on GAF with school type not adding further information as covariate $\left(\mathrm{F}_{(4)}=4.48, p=0.002\right)$.

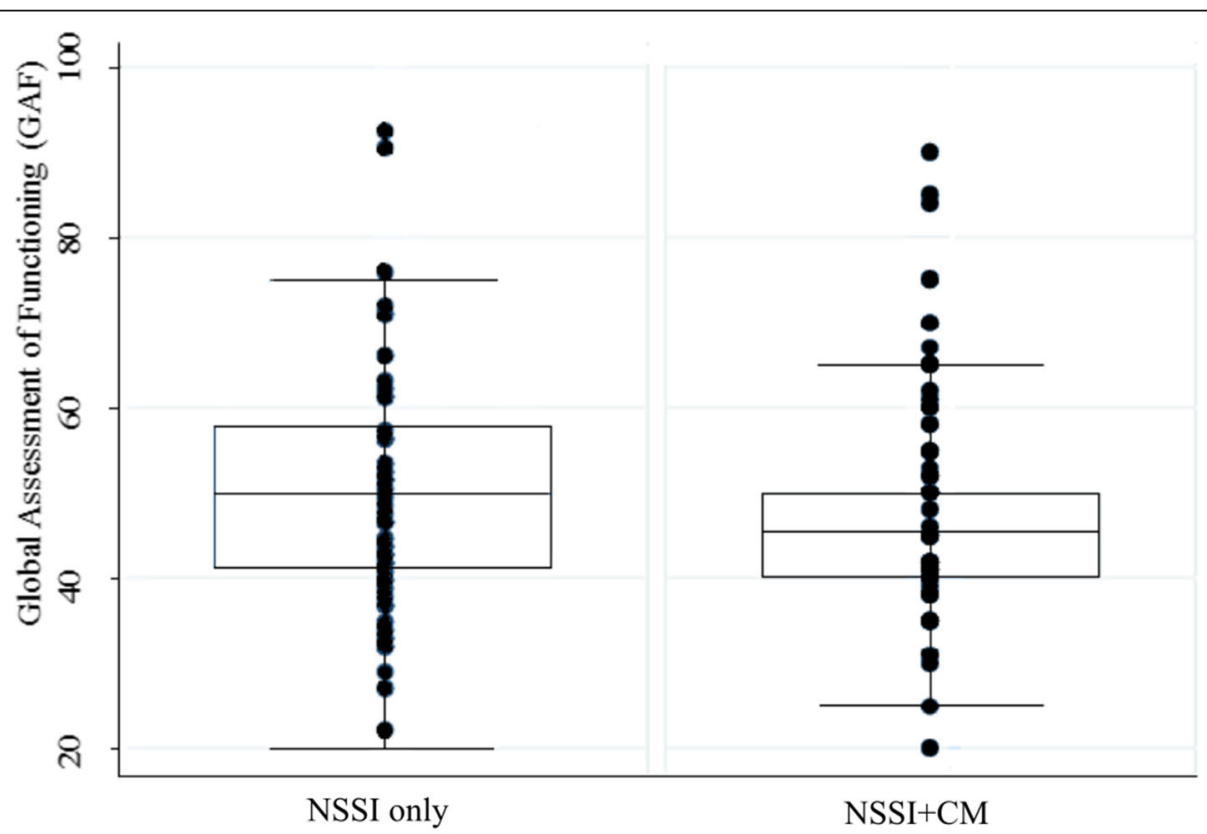

Fig. 1 Group differences between adolescents with NSSI only and adolescents with NSSI and CM on GAF 


\section{Structural equation model}

Before computing SEM, basic associations between all variables of interest (CM, BPD, depression, GAF) and possible confounding variables (sex, age) were tested. Pairwise correlation analysis yielded significant correlation between BPD, depression and GAF. Age was associated with number of BPD criteria and GAF but not with depression. Point biserial correlation showed significant effects of $\mathrm{CM}$ on all other variables of interest. Sex was associated with depression but not with BPD and GAF. Šidák- corrected correlation coefficients, point biserial effect sizes and respective $p$-values are reported in Table 2.

Based on the NSSI sample the first model (2.1) included all direct paths between the variables CM, BPD, depression and GAF. To account for confounding effects, covariance between BPD and depression was added to the model and additional paths from sex $\rightarrow$ depression and age $\rightarrow$ BPD/GAF. An additional model integrating PTSD diagnosis as a third potential mediator neither revealed a significant effect for PTSD nor did it

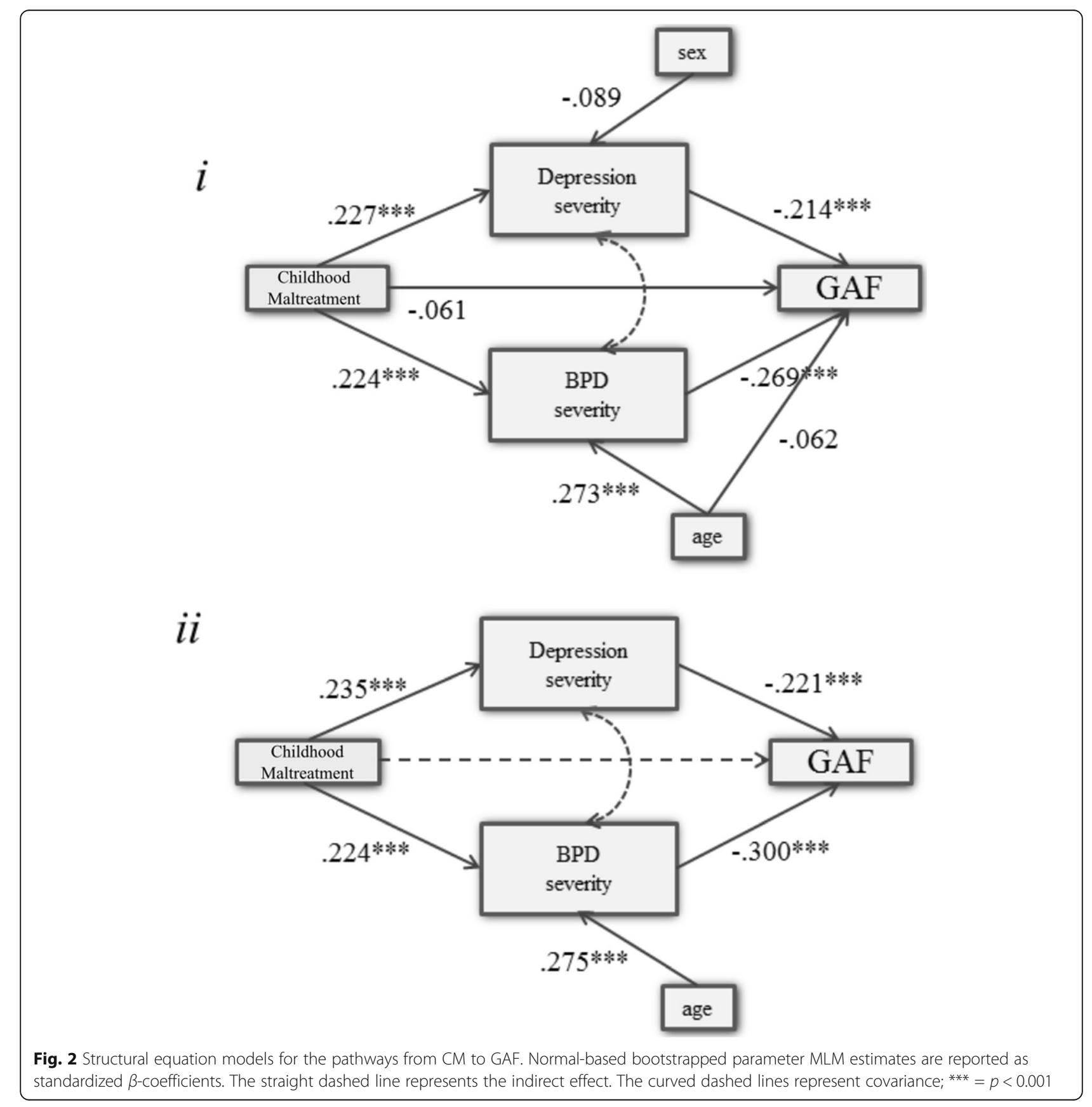


explain additional variance in the data; thus, PTSD was renounced in the final model.

CM directly predicted BPD and depression severity. $\mathrm{BPD}$ and depression severity further directly predicted GAF. The direct pathway from CM to GAF did not reach significance in this model. Sex had no influence on depression and age was only associated with BPD but not with GAF. The model provided a good fit $(\mathrm{CFI}=$ 0.998, TLI $=0.991$, RMSEA $=0.018$ ). In the next step, non-significant paths were eliminated for parsimony (model 2.2). All the ML-based parameter estimates were statistically significant $(p<0.001)$. CM predicted GAF only indirectly via BPD symptoms and depression severity. Model 2.2 yielded better GOF than model i (CFI = 0.999 , TLI $=0.997$, RMSEA $<0.012$ ). Standardized coefficients and CIs are reported in Table 3. The computed SEMs are illustrated in Fig. 2.

\section{Model with categorical diagnoses}

In order to validate the results from SEM, linear regression analyses with CM as predictor for GAF were calculated in the total sample. CM significantly predicted GAF in the regression model $\left(\mathrm{F}_{(1.338)}=9.54, p=.002\right)$. However, when categorical BPD and current depression diagnoses were taken into the regression model as covariates, $\mathrm{CM}$ as predictor for GAF had no significant value $(\beta=-1.94, \mathrm{t}=-1.51, p=.133)$ compared to BPD $(\beta=-$ 6.87, $\mathrm{t}=-5.75, p<.001)$ and depression $(\beta=-4.11, \mathrm{t}=$ $-3.50, p=.001$ ), with the model itself yielding a significant result $\left(\mathrm{F}_{(3.336)}=17.62, p<.001\right)$. Adding sex and school type as covariates did not significantly add further explanation of variance.

\section{Discussion}

Our results demonstrate that adolescents with NSSI and $\mathrm{CM}$ have significantly lower levels of psychosocial

Table 2 Pairwise correlation ( $r$ ) matrix and point biserial correlation $\left(r_{\text {pb }}\right)$ effect sizes

\begin{tabular}{|c|c|c|c|}
\hline Variables & BPD & DIKJ & GAF \\
\hline \multicolumn{4}{|l|}{ Pairwise } \\
\hline Age & $0.282^{* * *}$ & -0.006 & $-0.139^{*}$ \\
\hline BPD & - & $0.242^{* * *}$ & $-0.353^{* * *}$ \\
\hline DIKJ & & - & $-0.293^{* * *}$ \\
\hline GAF & & & - \\
\hline \multicolumn{4}{|c|}{ Point-biserial } \\
\hline $\mathrm{CM}$ & $.236^{* * *}$ & $.235^{* * *}$ & $-.178^{* * *}$ \\
\hline Sex & 0.073 & $0.127^{*}$ & -0.013 \\
\hline
\end{tabular}

Table 3 Bootstrapped standardized $\beta$-coefficients and confidence intervals (Cls) for the structural equation models

\begin{tabular}{|c|c|c|c|c|c|}
\hline & $\beta$ & SD & $p$ & $95 \% \mathrm{Cl}$ & \\
\hline \multicolumn{6}{|l|}{2.1} \\
\hline \multicolumn{6}{|l|}{ BPD } \\
\hline CM & 0.224 & 0.045 & $<0.001$ & 0.136 & 0.312 \\
\hline age & 0.273 & 0.042 & $<0.001$ & 0.190 & 0.355 \\
\hline \multicolumn{6}{|l|}{ Depression } \\
\hline CM & 0.227 & 0.043 & $<0.001$ & 0.143 & 0.311 \\
\hline sex & -0.089 & 0.465 & 0.056 & -0.180 & 0.002 \\
\hline \multicolumn{6}{|l|}{ GAF } \\
\hline $\mathrm{BPD}$ & -0.269 & 0.050 & $<0.001$ & -0.366 & -0.172 \\
\hline Depression & -0.214 & 0.522 & $<0.001$ & -0.316 & -0.111 \\
\hline$C M$ & -0.061 & 0.059 & 0.297 & -0.176 & 0.054 \\
\hline age & -0.062 & 0.043 & 0.148 & -0.145 & 0.022 \\
\hline \multicolumn{6}{|l|}{2.2} \\
\hline \multicolumn{6}{|l|}{ BPD } \\
\hline CM & 0.224 & 0.055 & $<0.001$ & 0.116 & 0.332 \\
\hline age & 0.275 & 0.038 & $<0.001$ & 0.200 & 0.349 \\
\hline \multicolumn{6}{|l|}{ Depression } \\
\hline CM & 0.235 & 0.058 & $<0.001$ & 0.122 & 0.348 \\
\hline \multicolumn{6}{|l|}{ GAF } \\
\hline BPD & -0.300 & 0.042 & $<0.001$ & -0.383 & -0.216 \\
\hline Depression & -0.221 & 0.054 & $<0.001$ & -0.327 & -0.114 \\
\hline
\end{tabular}

functioning (lower GAF scores) than adolescents engaging in NSSI who do not report CM. They also suggest that $\mathrm{CM}$ is indirectly linked with lower psychosocial functioning such that severity of BPD and depression (but not PTSD) explains the differences in psychosocial functioning in NSSI adolescents with vs. without CM. Thus, our findings are in line with prior work suggesting that individuals with mental disorder and additional CM differ from individuals without CM in their level of functioning $[30,31]$, and that these differences can be explained by different symptom profiles and more severe mental disorder [38-40, 43, 51, 74]. They contribute to the ongoing debate as to whether mentally ill individuals presenting with $\mathrm{CM}$ and those with the same mental disorder but without CM may represent specific ecophenotypes [39] but may rather suggest that $\mathrm{CM}$ is associated with higher illness severity of specific disorders.

Our study suggests that patients who report both NSSI and CM present with higher levels of BPD symptoms and depression severity and lower GAF scores. CM are uncontrollable and painful events that undermine the child's development of functional coping patterns, that are associated with cognitive and affective processing biases like hyperarousal or biased attention towards 
threat [75] and ineffective emotion regulation strategies already present in NSSI [76, 77].

Besides its contribution to the accumulation of dysfunctional emotion regulation strategies, CM contributes to a range of further problems such as retraumatization, adverse environments and bullying experiences [78-81] that can further fuel emotional and behavioral problems in already vulnerable adolescents, contributing to more severe conditions that are associated with significantly poorer functioning. Thus, CM may serve as an amplifying factor for higher levels of distress and lower levels of functioning in NSSI adolescents that are already at risk.

Our findings indicate that severity of BPD and depression is independently linked with psychosocial functioning and that both disorders equally explain variance in psychosocial functioning. Both disorders are strongly linked with poor emotion regulation [82, 83] and associated with impaired psychosocial functioning [46-48]. Future studies should examine whether emotion dysregulation may be a common factor explaining the relevance of both disorders with regard to psychosocial functioning. A PTSD diagnosis did not explain further variance in the model. Prior work has suggested that a relatively low percentage of adolescents who report CM also meet criteria for PTSD, whereas BPD and depression seem to be more frequently diagnosed in adolescents with NSSI $[45,59]$ In line with this, in the current sample, $62.8 \%$ had a diagnosis of depression and $37.0 \%$ had a diagnosis of BPD, whereas only $6.52 \%$ of patients had a diagnosis of PTSD. This low prevalence of PTSD in our and other samples may be due to the nature of traumatic experiences assessed: Our assessment using the CECA. Q was mainly focused on chronic and enduring childhood adversity within the family environment (Complex or Type-II trauma), which has been shown to be specifically associated with depression and personality disorder development and may not be as strongly associated with PTSD [24, 35, 38, $49,52]$. The discussion around diagnosing a trauma-related disorder in patients with complex $\mathrm{CM}$ is an issue of intense scientific debate [84]. After the notion of a separate trauma-related disorder for patients suffering from complex trauma was rejected in the DSM, the emergence of the diagnosis of "complex PTSD" in the new ICD-11 will certainly give new impulses. However, it would have been very interesting to be able to examine the effects of complex PTSD in our sample. Unfortunately, we did not implement measures to assess of this specific symptom profile in order to be able to include the respective information in our models.

\section{Limitations}

The cross-sectional nature of our study does not permit causal interpretations. Future studies would benefit from longitudinal designs that allowed to draw conclusions about the effects of CM on the development and severity of mental disorders and psychosocial functioning over time. Further, we implemented only one index of psychosocial functioning, the GAF. There have been some concerns regarding the GAF's reliability and validity $[75$, 85]. When the present study was designed in 2013, the GAF was chosen based on its widespread use as a clinical rating tool within the DSM-IV. Future studies should implement measures with more satisfying psychometric properties. Adolescents' CM assessment was based on retrospective self-reports that could reflect bias of autobiographical memory rather than the influence of the event per se. A recent meta-analysis pointed out that there is poor agreement between prospective and retrospective measures of $\mathrm{CM}$, and that those two types of measures identify largely different groups of individuals [86]. At the same time, studies report that prospectively and retrospectively assessed CM seems to be linked with similarly elevated risk of mental disorder, suggesting a robust effect of CM in both types of measures [24, 87]. We further did not assess at what age exactly maltreatment experiences occurred. Prior work has indicated that individuals with experiences of maltreatment before the age of 12 are at higher risk for depression, while those experiencing maltreatment after 12 years are at higher risk for PTSD [88]. Further, childhood maltreatment between three and five years of age is associated with more adverse mental health outcomes in adulthood than maltreatment earlier or later in childhood [74]. These findings highlight the importance of sensitive time periods and their prognostic influence on mental disorder that should be implemented in future research designs. Further, our analyses were based on a dichotomous (yes/no) CM variable that does not specify distinct types and severity of maltreatment events. Research shows that different forms of childhood maltreatment predict unique variance in emotion regulation strategies [89] that could specifically be associated with mental disorder. Yet, the aim of the study was to investigate a global effect of $\mathrm{CM}$ without a focus on a potential dose-response-relationship.

It should be mentioned that the sample was predominantly female. Further research should address if the reported associations may vary depending on sex. Unfortunately, the small number of male adolescents in our sample did not permit these additional analyses. Lastly, our sample consisted of individuals with NSSI disorder, and comorbidity was rather high. We based our analyses on the most frequently reported disorders, BPD and depression, and further included PTSD, however, other psychiatric disorders such as anxiety might have influenced our findings. Further research could examine whether the reported findings can be replicated 
in samples with a different distribution of comorbid disorders.

\section{Conclusion}

To the best of our knowledge, this is the first study to investigate the association of $\mathrm{CM}$ and psychosocial functioning in a large clinical sample of adolescents with NSSI which further implemented clinical expert ratings of psychosocial functioning. Our results implicate that clinicians need to be aware that additional CM may render adolescents with NSSI more vulnerable for more severe disorders and thus lower psychosocial functioning. Specifically, BPD and depression should be targeted in order to support NSSI patients and increase psychosocial functioning. Specialized treatments for adolescents such as dialectical-behavioral therapy (DBT-A) or mentalization-based therapy (MBT-A) are reported to be effective in reducing symptoms of emotion dysregulation, depression and interpersonal problems in these clinical populations $[90,91]$. Furthermore, promising effects of a short-term intervention on NSSI with similar effect sizes have recently been published [92]. BPD and depression are treatable, and therapeutic interventions may buffer adverse effects of CM in adolescents with NSSI.

\section{Acknowledgements}

Not applicable.

\section{Authors' contributions}

Michael Kaess designed the study and wrote the protocol. Denisa Ghinea, Anna Fuchs and Julian Koenig were involved in the implementation and recruitment of the study. Peter Parzer undertook the statistical analysis, and Denisa Ghinea wrote the first draft of the manuscript. Anna Fuchs, Julian Koenig, Franz Resch and Michael Kaess corrected and revised the first and final drafts. All authors contributed to and have approved the final manuscript.

\section{Funding}

We gratefully acknowledge the financial support of the AtR!Sk-cohort study provided by the Dietmar Hopp Foundation (grant number 23011121).

\section{Availability of data and materials}

The datasets used and/or analyzed during the current study are available from the corresponding author on reasonable request.

\section{Declarations}

Ethics approval and consent to participate

The data were collected at baseline of the ongoing AtR!Sk cohort study, which was approved by the Ethical Committee of the Medical Faculty, Heidelberg University, Germany (Study: ID S-449/2013) in accordance to the Declaration of Helsinki. Informed and written consent was provided by adolescents and their parents or other caregivers prior to inclusion in the study.

\section{Consent for publication}

Not applicable.

\section{Competing interests}

The authors were independent of the funders in all aspects of study design, data analysis, and writing of this manuscript and have no competing of interest to declare.
Received: 9 November 2020 Accepted: 31 May 2021

Published online: 01 July 2021

\section{References}

1. Ro E, Clark LA. Psychosocial functioning in the context of diagnosis: assessment and theoretical issues. Psychol Assess. 2009;21(3):313-24. https:// doi.org/10.1037/a0016611.

2. Skodol AE. Impact of personality pathology on psychosocial functioning. Curr Opin Psychol. 2018;21:33-8. https://doi.org/10.1016/j.copsyc.2017.09. 006.

3. Washburn JJ, Potthoff LM, Juzwin KR, Styer DM. Assessing DSM-5 nonsuicidal self-injury disorder in a clinical sample. Psychol Assess. 2015; 27(1):31-41. https://doi.org/10.1037/pas0000021.

4. Andover MS. Non-suicidal self-injury disorder in a community sample of adults. Psychiatry Res. 2014;219(2):305-10. https://doi.org/10.1016/j. psychres.2014.06.001.

5. In-Albon T. Nonsuicidal self-injury in adolescents. Eur Psychol. 2015;20(3): 167-75. https://doi.org/10.1027/1016-9040/a000229.

6. American Psychiatric Association. Diagnostic and statistical manual of mental disorders. 5th ed. Washington, DC: Author; 2013.

7. Muehlenkamp JJ, Claes L, Havertape L, Plener PL. International prevalence of adolescent non-suicidal self-injury and deliberate self-harm. Child Adolesc Psychiatry Ment Health. 2012;6:10.

8. Swannell SV, Martin GE, Page A, Hasking P, John NJS. Prevalence of nonsuicidal self-injury in nonclinical samples: systematic review, metaanalysis and meta-regression. Suicide Life Threat Behav. 2014;44(3):273-303. https://doi.org/10.1111/sltb.12070.

9. Kaess M, Parzer P, Mattern M, Plener PL, Bifulco A, Resch F, et al. Adverse childhood experiences and their impact on frequency, severity, and the individual function of nonsuicidal self-injury in youth. Psychiatry Res. 2013; 206(2-3):265-72. https://doi.org/10.1016/j.psychres.2012.10.012.

10. Plener PL, Schumacher TS, Munz LM, Groschwitz RC. The longitudinal course of non-suicidal self-injury and deliberate self-harm: a systematic review of the literature. Borderline Personal Disord Emot Dysregulation. 2015;2(1):2. https://doi.org/10.1186/s40479-014-0024-3.

11. Glenn CR, Klonsky ED. Nonsuicidal self-injury disorder: an empirical investigation in adolescent psychiatric patients. J Clin Child Adolesc Psychol Off J Soc Clin Child Adolesc Psychol Am Psychol Assoc Div 53. 2013;42(4): 496-507.

12. Nock MK, Joiner TE, Gordon KH, Lloyd-Richardson E, Prinstein MJ. Nonsuicidal self-injury among adolescents: diagnostic correlates and relation to suicide attempts. Psychiatry Res. 2006;144(1):65-72. https://doi.org/10.1016/j. psychres.2006.05.010.

13. Zetterqvist M, Lundh L-G, Dahlström Ö, Svedin CG. Prevalence and function of non-suicidal self-injury (NSSI) in a community sample of adolescents, using suggested DSM-5 criteria for a potential NSSI disorder. J Abnorm Child Psychol. 2013;41(5):759-73. https://doi.org/10.1007/s10802-013-9712-5.

14. In-Albon T, Ruf C, Schmid M. Proposed diagnostic criteria for the DSM-5 of nonsuicidal self-injury in female adolescents: diagnostic and clinical correlates. Psychiatry J. 2013;2013:159208.

15. Möller HJ. Rating depressed patients: observer- vs self-assessment. Eur Psychiatry. 2000;15(3):160-72. https://doi.org/10.1016/S0924-9338(00)00229-7.

16. Myers K, Winters NC. Ten-year review of rating scales. I: overview of scale functioning, psychometric properties, and selection. J Am Acad Child Adolesc Psychiatry. 2002;41(2):114-22. https://doi.org/10.1097/00004583-2 00202000-00004.

17. Carr CP, Martins CMS, Stingel AM, Lemgruber VB, Juruena MF. The role of early life stress in adult psychiatric disorders: a systematic review according to childhood trauma subtypes. J Nerv Ment Dis. 2013;201(12):1007-20. https://doi.org/10.1097/NMD.0000000000000049.

18. Bolger KE, Patterson CJ. Developmental pathways from child maltreatment to peer rejection. Child Dev. 2001;72(2):549-68. https://doi.org/10.1111/14 67-8624.00296.

19. Ports KA, Ford DC, Merrick MT. Adverse childhood experiences and sexual victimization in adulthood. Child Abuse Negl. 2016;51:313-22. https://doi. org/10.1016/j.chiabu.2015.08.017.

20. Finkelhor D, Ormrod RK, Turner HA. Re-victimization patterns in a national longitudinal sample of children and youth. Child Abuse Negl. 2007;31(5): 479-502. https://doi.org/10.1016/j.chiabu.2006.03.012.

21. Wolff N, Shi J. Childhood and adult trauma experiences of incarcerated persons and their relationship to adult behavioral health problems and 
treatment. Int J Environ Res Public Health. 2012;9(5):1908-26. https://doi. org/10.3390/ijerph9051908.

22. lachini AL, Petiwala AF, DeHart DD. Examining adverse childhood experiences among students repeating the ninth grade: implications for school dropout prevention. Child Sch. 2016;38(4):218-27. https://doi.org/1 $0.1093 / \mathrm{cs} / \mathrm{cdw} 029$

23. Porche MV, Fortuna LR, Lin J, Alegria M. Childhood trauma and psychiatric disorders as correlates of school dropout in a National Sample of young adults. Child Dev. 2011;82(3):982-98. https://doi.org/10.1111/j.1467-8624.2010.01534.X.

24. Norman RE, Byambaa M, De R, Butchart A, Scott J, Vos T. The long-term health consequences of child physical abuse, emotional abuse, and neglect: a systematic review and meta-analysis. PLoS Med. 2012;9(11):e1001349. https://doi.org/10.1371/journal.pmed.1001349.

25. Gruhn MA, Compas BE. Effects of maltreatment on coping and emotion regulation in childhood and adolescence: a meta-analytic review. Child Abuse Negl. 2020;103(104446).

26. McCrory E, De Brito SA, Viding E. Research review: the neurobiology and genetics of maltreatment and adversity. J Child Psychol Psychiatry. 2010; 51(10):1079-95. https://doi.org/10.1111/j.1469-7610.2010.02271.X.

27. Lansford JE, Dodge KA, Pettit GS, Bates JE, Crozier J, Kaplow J. A 12-year prospective study of the long-term effects of early child physical maltreatment on psychological, behavioral, and academic problems in adolescence. Arch Pediatr Adolesc Med. 2002;156(8):824-30. https://doi. org/10.1001/archpedi.156.8.824

28. Rogosch FA, Cicchetti D, Aber JL. The role of child maltreatment in early deviations in cognitive and affective processing abilities and later peer relationship problems. Dev Psychopathol. 1995 ed;7(4):591-609.

29. Shonkoff JP, Garner AS. The committee on psychosocial aspects of child and family health $\mathrm{C}$ on EC, Siegel BS, dobbins MI, earls MF, et al. the lifelong effects of early childhood adversity and toxic stress. Pediatrics. 2012;129(1): e232-46. https://doi.org/10.1542/peds.2011-2663.

30. Heim C, Newport DJ, Mletzko T, Miller AH, Nemeroff CB. The link between childhood trauma and depression: insights from HPA axis studies in humans. Psychoneuroendocrinology. 2008;33(6):693-710. https://doi.org/1 0.1016/.jpsyneuen.2008.03.008.

31. Schiweck C, Piette D, Berckmans D, Claes S, Vrieze E. Heart rate and high frequency heart rate variability during stress as biomarker for clinical depression. A systematic review. Psychol Med. 2019;49(2):200-11. https://doi. org/10.1017/S0033291718001988.

32. Martin J, Bureau J-F, Cloutier P, Lafontaine M-F. A comparison of invalidating family environment characteristics Between University students engaging in Self-Injurious Thoughts \& Actions and non-self-Injuring University students. J Youth Adolesc. 2011;40(11):1477-88. https://doi.org/10.1007/s10964-0119643-9.

33. Thomassin K, Shaffer A, Madden A, Londino DL. Specificity of childhood maltreatment and emotion deficit in nonsuicidal self-injury in an inpatient sample of youth. Psychiatry Res. 2016;244:103-8.

34. Isohookana R, Riala K, Hakko H, Räsänen P. Adverse childhood experiences and suicidal behavior of adolescent psychiatric inpatients. Eur Child Adolesc Psychiatry. 2013;22(1):13-22. https://doi.org/10.1007/s00787-012-0311-8.

35. Li M, D'Arcy C, Meng X. Maltreatment in childhood substantially increases the risk of adult depression and anxiety in prospective cohort studies: systematic review, meta-analysis, and proportional attributable fractions. Psychol Med. 2016;46(4):717-30. https://doi.org/10.1017/50033291715002 743.

36. Widom CS, DuMont K, Czaja SJ. A prospective investigation of major depressive disorder and comorbidity in abused and neglected children grown up. Arch Gen Psychiatry. 2007;64(1):49-56. https://doi.org/10.1001/a rchpsyc.64.1.49.

37. Danese A, Moffitt TE, Harrington H, Milne BJ, Polanczyk G, Pariante CM, et al. Adverse childhood experiences and adult risk factors for age-related disease: depression, inflammation, and clustering of metabolic risk markers Arch Pediatr Adolesc Med. 2009;163(12):1135-43. https://doi.org/10.1001/a rchpediatrics.2009.214.

38. Felitti VJ, Anda RF, Nordenberg D, Williamson DF, Spitz AM, Edwards V, et al. Relationship of childhood abuse and household dysfunction to many of the leading causes of death in adults. The adverse childhood experiences (ACE) study. Am J Prev Med. 1998;14(4):245-58. https://doi.org/10.1016/S0749-3 797(98)00017-8.

39. Teicher MH, Samson JA. Childhood maltreatment and psychopathology: a case for ecophenotypic variants as clinically and Neurobiologically distinct subtypes. Am J Psychiatry. 2013;170(10):1114-33. https://doi.org/10.1176/a ppi.ajp.2013.12070957.

40. Agnew-Blais J, Danese A. Childhood maltreatment and unfavourable clinical outcomes in bipolar disorder: a systematic review and meta-analysis. Lancet Psychiatry. 2016;3(4):342-9. https://doi.org/10.1016/52215-0366(15)00544-1.

41. Harkness KL, Wildes JE. Childhood adversity and anxiety versus dysthymia co-morbidity in major depression. Psychol Med. 2002;32(7):1239-49. https:// doi.org/10.1017/S0033291702006177.

42. Hovens JGFM, Giltay EJ, Wiersma JE, Spinhoven P, Penninx BWJH, Zitman FG. Impact of childhood life events and trauma on the course of depressive and anxiety disorders. Acta Psychiatr Scand. 2012;126(3):198-207. https://doi. org/10.1111/j.1600-0447.2011.01828.x.

43. Nanni V, Uher R, Danese A. Childhood maltreatment predicts unfavorable course of illness and treatment outcome in depression: a meta-analysis. Am J Psychiatry. 2012;169(2):141-51. https://doi.org/10.1176/appi.ajp.2011.1102 0335 .

44. Groschwitz RC, Plener PL, Kaess M, Schumacher T, Stoehr R, Boege I. The situation of former adolescent self-injurers as young adults: a follow-up study. BMC Psychiatry. 2015;15(1):160. https://doi.org/10.1186/s12888-015-0555-1.

45. Ghinea D, Edinger A, Parzer P, Koenig J, Resch F, Kaess M. Non-suicidal selfinjury disorder as a stand-alone diagnosis in a consecutive help-seeking sample of adolescents. J Affect Disord. 2020;274:1122-5. https://doi.org/10.1 016/j.jad.2020.06.009

46. Cambridge OR, Knight MJ, Mills N, Baune BT. The clinical relationship between cognitive impairment and psychosocial functioning in major depressive disorder: a systematic review. Psychiatry Res. 2018;269:157-71. https://doi.org/10.1016/j.psychres.2018.08.033.

47. Zeitler M-L, Bohus M, Kleindienst N, Knies R, Ostermann M, Schmahl C, et al. How to assess recovery in borderline personality disorder: psychosocial functioning and satisfaction with life in a sample of former DBT study patients. J Personal Disord. 2020;34(3):289-307. https:/doi.org/10.1521/pedi_2018_32_394.

48. Kramer $U$, Temes CM, Magni LR, Fitzmaurice GM, Aguirre BA, Goodman M, et al. Psychosocial functioning in adolescents with and without borderline personality disorder. Personal Ment Health. 2017;11(3):164-70. https://doi. org/10.1002/pmh.1377.

49. Infurna MR, Brunner R, Holz B, Parzer P, Giannone F, Reichl C, et al. The specific role of childhood abuse, parental bonding, and family functioning in female adolescents with borderline personality disorder. J Personal Disord. 2016;30(2):177-92. https://doi.org/10.1521/pedi_2015_29_186.

50. Zanarini MC, Yong L, Frankenburg FR, Hennen J, Reich DB, Marino MF, et al. Severity of reported childhood sexual abuse and its relationship to severity of borderline psychopathology and psychosocial impairment among borderline inpatients. J Nerv Ment Dis. 2002;190(6):381-7. https://doi.org/1 0.1097/00005053-200206000-00006.

51. Widom CS, Czaja SJ, Paris J. A prospective investigation of borderline personality disorder in abused and neglected children followed up into adulthood. J Personal Disord. 2009;23(5):433-46. https://doi.org/10.1521/ pedi.2009.23.5.433

52. Infurna MR, Reichl C, Parzer P, Schimmenti A, Bifulco A, Kaess M. Associations between depression and specific childhood experiences of abuse and neglect: a meta-analysis. J Affect Disord. 2016;190:47-55. https:// doi.org/10.1016/j.jad.2015.09.006.

53. Pietrek C, Elbert T, Weierstall R, Müller O, Rockstroh B. Childhood adversities in relation to psychiatric disorders. Psychiatry Res. 2013;206(1):103-10. https://doi.org/10.1016/j.psychres.2012.11.003.

54. Zanarini MC, Williams AA, Lewis RE, Reich RB, Vera SC, Marino MF, et al. Reported pathological childhood experiences associated with the development of borderline personality disorder. Am J Psychiatry. 1997; 154(8):1101-6. https://doi.org/10.1176/ajp.154.8.1101.

55. Hessels CJ, Laceulle OM, van Aken MA, Resch F, Kaess M. Differentiating BPD in adolescents with NSSI disorder: the role of adverse childhood experiences and current social relationships. Borderline Personal Disord Emot Dysregulation. 2018;5(1):1-11.

56. Nurius PS, Green S, Logan-Greene P, Borja S. Life course pathways of adverse childhood experiences toward adult psychological well-being: a stress process analysis. Child Abuse Negl. 2015;45:143-53. https://doi.org/1 0.1016/j.chiabu.2015.03.008.

57. Kalmakis KA, Chiodo LM, Kent N, Meyer JS. Adverse childhood experiences, post-traumatic stress disorder symptoms, and self-reported stress among traditional and nontraditional college students. J Am Coll Heal. 2020;68(4): 411-8. https://doi.org/10.1080/07448481.2019.1577860. 
58. Karatzias T, Shevlin M, Fyvie C, Grandison G, Garozi M, Latham E, et al. Adverse and benevolent childhood experiences in posttraumatic stress disorder (PTSD) and complex PTSD (CPTSD): implications for trauma-focused therapies. Eur J Psychotraumatol. 2020;11(1):1793599. https://doi.org/10.1 080/20008198.2020.1793599.

59. Dierkhising CB, Ko SJ, Woods-Jaeger B, Briggs EC, Lee R, Pynoos RS. Trauma histories among justice-involved youth: findings from the National Child Traumatic Stress Network. Eur J Psychotraumatol. 2013;4(1):20274. https:// doi.org/10.3402/ejpt.v4i0.20274

60. Kaess M, Ghinea D, Fischer-Waldschmidt G, Resch F. The outpatient Clinic for Adolescent Risk-taking and Self-harm behaviors (AtR!Sk) - a pioneering approach of outpatient early detection and intervention of borderline personality disorder. Prax Kinderpsychol Kinderpsychiatr. 2017;66(6):404-22. https://doi.org/10.13109/prkk.2017.66.6.404.

61. Wittchen H-U, Zaudig M, Fydrich T. Strukturiertes Klinisches Interview für DSM-IV. Achse I und II. Göttingen: Hogrefe; 1997.

62. First MB, Gibbon M, Spitzer RL, Williams JBW, Benjamin LS. Structured clinical interview for DSM-IV Axis II personality disorders, (SCID-II). Washington, DC: American Psychiatric Press, Inc.; 1997.

63. Chanen AM, Jackson HJ, McGorry PD, Allot KA, Clarkson V, Yuen HP. Two-year stability of personality disorder in older adolescent outpatients. J Personal Disord. 2004;18(6):526-41. https://doi.org/10.1521/pedi.18.6.526.54798.

64. Fischer G, Ameis N, Parzer P, Plener PL, Groschwitz R, Vonderlin E, et al. The German version of the self-injurious thoughts and behaviors interview (SITBI-G): a tool to assess non-suicidal self-injury and suicidal behavior disorder. BMC Psychiatry [Internet]. 2014;14 Available from: http://www.ncbi. nlm.nih.gov/pmc/articles/PMC4174267/, [cited 2017 Jan 10].

65. Sheehan DV, Shytle D, Milo K. Mini international neuropsychiatric interview for Chrildren and adolescents - M.I.N.I.-kid. Tampa, FL: Author; 2004.

66. Sheehan DV, Sheehan KH, Shytle RD, Janavs J, Bannon Y, Rogers JE, et al. Reliability and validity of the Mini international neuropsychiatric interview for children and adolescents (MINI-KID). J Clin Psychiatry. 2010;71(03):31326. https://doi.org/10.4088/JCP.09m05305whi.

67. Kovacs M. Children's depression inventory. North Tonawanda, NY: MultiHealth Systems, Inc; 1992.

68. Stiensmeier-Pelster J, Braune-Krickau M, Schürmann M, Duda K. DepressionsInventar für Kinder und Jugendliche (DIKJ). Handanweisung (3., überarb. u. neunorm. Aufl.). Göttingen: Hogrefe; 2014

69. Kaess M, Parzer P, Mattern M, Resch F, Bifulco A, Brunner R. Childhood experiences of care and abuse (CECA) - validation of the German version of the questionnaire and interview, and results of an investigation of correlations between adverse childhood experiences and suicidal behaviour. Z Kinder Jugendpsychiatr Psychother. 2011;39(4):243-52. https//doi.org/10.1024/1422-4917/a000115.

70. Bifulco A, Bernazzani O, Moran PM, Jacobs C. The childhood experience of care and abuse questionnaire (CECA.Q): validation in a community series. $\mathrm{Br}$ J Clin Psychol. 2005;44(Pt 4):563-81. https://doi.org/10.1348/014466505X3 5344.

71. American Psychiatric Association. Diagnostic and statistical manual of mental disorders. 4th ed. Washington, DC: Author; 1994.

72. Schermelleh-Engel $\mathrm{K}$, Moosbrugger $\mathrm{H}$, Müller $\mathrm{H}$. Evaluating the fit of structural equation models: tests of significance and descriptive goodnessof-fit measures. Methods Psychol Res Online. 2003;8(2):23-74.

73. World Health Organization (WHO). International Statistical Classification of Diseases and Related Health Problems (ICD-10). 2010.

74. Kaplow JB, Widom CS. Age of onset of child maltreatment predicts longterm mental health outcomes. J Abnorm Psychol. 2007;116(1):176-87. https://doi.org/10.1037/0021-843X.116.1.176.

75. Vatnaland T, Vatnaland J, Friis S, Opjordsmoen S. Are GAF scores reliable in routine clinical use? Acta Psychiatr Scand. 2007;115(4):326-30. https://doi. org/10.1111/j.1600-0447.2006.00925.x.

76. Briere J, Jordan CE. Childhood maltreatment, intervening variables, and adult psychological difficulties in women: an overview. Trauma Violence Abuse. 2009;10(4):375-88. https://doi.org/10.1177/1524838009339757.

77. Lalor K, McElvaney R. Child sexual abuse, links to later sexual exploitation/ high-risk sexual behavior, and prevention/treatment programs. Trauma Violence Abuse. 2010;11(4):159-77. https://doi.org/10.1177/15248380103782 99.

78. Jacobson CM, Muehlenkamp JJ, Miller AL, Turner JB. Psychiatric impairment among adolescents engaging in different types of deliberate self-harm. J Clin Child Adolesc Psychol Off J Soc Clin Child Adolesc Psychol Am Psychol Assoc Div 53. 2008;37(2):363-75.
79. Forster M, Gower AL, McMorris BJ, Borowsky IW. Adverse childhood experiences and school-based victimization and perpetration. J Interpers Violence. 2017;1:886260517689885.

80. Lewis CS, Jospitre T, Griffing S, Chu M, Sage RE, Madry L, et al. Childhood maltreatment, familial violence, and Retraumatization. J Emot Abus. 2006; 6(4):47-67. https://doi.org/10.1300/J135v06n04_03.

81. Whitfield CL, Anda RF, Dube SR, Felitti VJ. Violent childhood experiences and the risk of intimate partner violence in adults: assessment in a large health maintenance organization. J Interpers Violence. 2003;18(2):166-85. https://doi.org/10.1177/0886260502238733.

82. Chapman AL. Borderline personality disorder and emotion dysregulation. Dev Psychopathol. 2019:1-14.

83. Schäfer JÖ, Naumann E, Holmes EA, Tuschen-Caffier B, Samson AC. Emotion regulation strategies in depressive and anxiety symptoms in youth: a metaanalytic review. J Youth Adolesc. 2017;46(2):261-76. https://doi.org/10.1007/ s10964-016-0585-0.

84. Giourou E, Skokou M, Andrew SP, Alexopoulou K, Gourzis P, Jelastopulu E. Complex posttraumatic stress disorder: the need to consolidate a distinct clinical syndrome or to reevaluate features of psychiatric disorders following interpersonal trauma? World J Psychiatry. 2018;8(1):12-9. https://doi.org/10. 5498/wjp.v8.i1.12.

85. Aas IM. Global assessment of functioning (GAF): properties and frontier of current knowledge. Ann General Psychiatry. 2010;9(1):20. https://doi.org/1 0.1186/1744-859X-9-20.

86. Baldwin JR, Reuben A, Newbury JB, Danese A. Agreement between prospective and retrospective measures of childhood maltreatment: a systematic review and meta-analysis. JAMA Psychiatry. 2019;76(6):584-93. https://doi.org/10.1001/jamapsychiatry.2019.0097.

87. Scott KM, McLaughlin KA, Smith DA, Ellis PM. Childhood maltreatment and DSM-IV adult mental disorders: comparison of prospective and retrospective findings. Br J Psychiatry. 2012;200(6):469-75. https://doi.org/10.1192/bjp. bp.111.103267.

88. Schoedl AF, Costa MCP, Mari JJ, Mello MF, Tyrka AR, Carpenter LL, et al. The clinical correlates of reported childhood sexual abuse: an association between age at trauma onset and severity of depression and PTSD in adults. J Child Sex Abuse. 2010;19(2):156-70. https://doi.org/10.1080/10538711003615038.

89. O'Mahen HA, Karl A, Moberly N, Fedock G. The association between childhood maltreatment and emotion regulation: two different mechanisms contributing to depression? J Affect Disord. 2015;174:287-95. https://doi. org/10.1016/j.jad.2014.11.028.

90. Bürger A, Fischer-Waldschmidt G, Hammerle F, von Auer AK, Parzer P, Kaess M. Differential change of borderline personality disorder traits during dialectical behavior therapy for adolescents. J Personal Disord. 2019;32:1-16.

91. Rossouw TI, Fonagy P. Mentalization-based treatment for self-harm in adolescents: a randomized controlled trial. J Am Acad Child Adolesc Psychiatry. 2012;51(12):1304-1313.e3.

92. Kaess M, Edinger A, Fischer-Waldschmidt G, Parzer P, Brunner R, Resch F. Short-term cognitive behavioral intervention for the treatment of nonsuicidal self-injury in adolescents - A randomized controlled trial. Eur Child Adolesc Psychiatry. 2019.

\section{Publisher's Note}

Springer Nature remains neutral with regard to jurisdictional claims in published maps and institutional affiliations.

Ready to submit your research? Choose BMC and benefit from:

- fast, convenient online submission

- thorough peer review by experienced researchers in your field

- rapid publication on acceptance

- support for research data, including large and complex data types

- gold Open Access which fosters wider collaboration and increased citations

- maximum visibility for your research: over $100 \mathrm{M}$ website views per year

At $\mathrm{BMC}$, research is always in progress.

Learn more biomedcentral.com/submission 